\title{
The Effectiveness of Physical Therapy Interventions for Fatigue in Multiple Sclerosis Patients: A Systematic Review
}

\author{
MUSTAFA I. AHMED, M.Sc.*; ABEER A. ELWISHY, Ph.D.*; MAHMOUD Y. ELZANATY, Ph.D.* and \\ NEVIN M. SHALABY, M.D.** \\ The Department of Physical Therapy for Neuromuscular Disorders and its Surgery, Faculty of Physical Therapy* and \\ The Department of Neurology, Faculty of Medicine**, Cairo University
}

\begin{abstract}
Background: Patients with MS commonly report problems with walking, balance, fatigue and visual disturbances. These symptoms can appear suddenly, they have a variable course and they differ in severity. Among the frequently encountered symptoms in MS, fatigue remains the most challenging one, majorly altering the quality of life. It affects up to $80 \%$ ofMS patients.
\end{abstract}

Aim of Study: The aim of this systematic review was to examine the effectiveness of physical therapy interventions for fatigue in multiple sclerosis patients.

Material and Methods: Thecurrent study was made on patients with multiple sclerosis aged $\geq 18$ years. We searched the PubMed, Pedro, Cochrane and goggle scholar web site from inception up till now. Systematic review of randomized controlled trials, the intervention used was physical therapy interventions as a group programs. Nine studies were selected according to inclusive and exclusive criteria and descriptive analysis were conducted due to heterogeneity.

Results: Seven studies assessed fatigue by physical therapy interventions in multiple sclerosis patients. There was very high heterogeneity in fatigue severity scale among studies ( $\mathrm{n}=7$ studies, $\mathrm{n}=941$ participants, $\left.p<0.00001 ; \mathrm{I}^{2}=95 \%\right)$. There was significant overall effect between exercise therapy group and control group in fatigue by fatigue severity scale (SMD= $-1.24 ; 95 \%$ CI, -1.38 to $-1.10 ; p<0.00001)$, two studies assessed fatigue by physical therapy interventions in multiple sclerosis patients. There was very high heterogeneity in modified fatigue impact scale among studies ( $\mathrm{n}=2$ studies, $\mathrm{n}=$ 131 participants, $p=0.004 ; \mathrm{I}^{2}=88 \%$ ). There was significant overall effect between exercise therapy group and control group in fatigue by modified fatigue impact scale (SMD= $-0.57 ; 95 \% \mathrm{CI},-0.93$ to $-0.22 ; p=0.002$ ) three studies assessed fatigue by physical therapy interventions in multiple sclerosis patients. There was very high heterogeneity in visual analogue scale among studies $(\mathrm{n}=3$ studies, $\mathrm{n}=234$ participants, $p$ $<0.00001 ; \mathrm{I}^{2}=98 \%$ ). There was significant overall effect between exercise therapy group and control group in fatigue by visual analogue scale $(\mathrm{SMD}=0.96 ; 95 \% \mathrm{CI}, 0.66$ to 1.27 ;

Correspondence to: Dr. Mustafa I. Ahmed, The Department of Physical Therapy for Neuromuscular Disorders and its Surgery, Faculty of Physical Therapy, Cairo University $p<0.00001$ ), four studies assessed fatigue by physical therapy interventions in multiple sclerosis patients. There was no heterogeneity in multiple sclerosis quality of life-54 among studies ( $\mathrm{n}=4$ studies, $\mathrm{n}=177$ participants, $p=0.62 ; \mathrm{I}=0 \%$ ). There was significant overall effect between exercise therapy group and control group in fatigue by multiple sclerosis quality of life-54 (SMD=0.35; 95\% CI, 0.05 to $0.65 ; p=0.02$ ). Sensitivity analysis showed that fatigue assessed by multiple sclerosis quality of life- 54 was non-significant by excluding one trial at a time from pooled effects to determine whether any one study was particularly influential. No significant or change in heterogeneity $\left(\mathrm{I}^{2}=0 \%\right)$ among including four studies was observed after removal one study according to sensitivity analysis matrix.

Conclusion: The current level of evidence supports the effectiveness of physical therapy interventions for reducing fatigue in multiple sclerosis patients.

Key Words: Systematic review - Physical therapy interventions - Fatigue - Multiple sclerosis.

\section{Introduction}

MULTIPLE Sclerosis (MS) is a chronic progressive inflammatory disease of the Central Nervous System (CNS) and represents the major cause of non-traumatic disability in young adults [1].

Its estimated prevalence in Europe is 83 per 100,000 , with rates being approximately twice as high for women as for men and lower in the southern than in the northern European countries [2].

In a previous Egyptian retrospective metaanalysis study in different referral centers, including five centers in Cairo metropolitan, and five other centers in different governorates, the prevalence of MS in Egypt was found to be 14.1/100,000 [3].

Persons with MS commonly report problems with walking, balance, fatigue and visual disturbances [4]. These symptoms can appear suddenly, they have a variable course and they differ in 
severity. They all, however, progress with age and ultimately can have a devastating impact on the health and quality of life [5].

Among the frequently encountered symptoms in MS, fatigue remains the most challenging one, majorly altering the quality of life [6]. Indeed, it affects up to $80 \%$ of MS patients at some point in their disease course, gets exacerbated during the day, and increases with hot and humid environment [7-9].

Due to the prevalence, disabling character, and unexplained aetiology of fatigue in MS, the number of trials investigating Physical Therapy (PT) interventions and included fatigue as an outcome, has grown exponentially in the 2000 s. In addition, a number of studies have suggested that nonpharmacological interventions such as PT may have beneficial effects in the treatment of fatigue in other diseases, such as chronic fatigue syndrome, and cancer [10,11].

The MS Council for Clinical Practice Guidelines (MSCCP) defined fatigue as a "subjective lack of physical and mental energy that is perceived by the individual or caregiver to interfere with usual and desired activities [12].

PT interventions that are used in treatment of MS related fatigue include exercise therapy, vestibular rehabilitation, electromagnetic field and aquatic exercises.

An efficient rehabilitation strategy is exercise therapy, but its role in MS rehabilitation has been a controversial issue. For years, patients with MS were advised not to participate in exercise because it was reported to lead to worsening of symptoms or fatigue [13]. During the past decades, however, studies on exercise therapy in MS have shown promising effects [14]. Recently, it has been suggested that exercise in general possesses the potential to reduce MS fatigue [15].

Another PT intervention that is used in treatment of fatigue in MS patients is vestibular rehabilitation. vestibular rehabilitation program demonstrated both statistically significant and clinically relevant change in fatigue, impaired balance, and disability due to dizziness or disequilibrium in patients with MS [16].

Also, electromagnetic field can be used. Sandyk reported cases of prompter recovery from fatigue following physical activity by extracranially applied electromagnetic field [17].
Aquatic exercise therapy can effectively improve fatigue and physical and mental HRQOL in patients with MS [18].

Systematic reviews and meta-analysis lie on top of the evidence pyramid both in public health and clinical medicine [19]. Decision making is the process by which evidence is (or is not) applied to practice. The statement "evidence alone does not make decisions, people do" reflects the integral role of the therapist in translation of evidence to practice. Therapists make decisions on complex issues related to examination, prognosis, expected outcomes, the plan of care, and coordination of care on a daily basis [20].

\section{Material and Methods}

A systematic search was conducted for best research evidence for the effectiveness of physical therapy interventions for fatigue in multiple sclerosis patients; using bibliographic databases.

Eligibility criteria: Studies will be selected according to the criteria outlined below.

Types of studies: Randomized Controlled Trials (RCTs) and randomized cross-over studies will be eligible.

Types of participants: Studies on adult patients ( $\geq 18$ years), with the clinical confirmed diagnosis of MS according to applicable diagnostic criteria [21-24], will be eligible.

Interventions: All PT interventions, which targeted treatment of fatigue in patients with MS, will be included. Also studies, where fatigue treatment was used as an outcome measure to evaluate the effectiveness of PT interventions with a different primary focus, will be included.

PT interventions, in this review, refer to treatments carried out by the physical therapists where the type of procedural intervention was one that is included in the Guide to PT Practice of the American PT Association [25].

Comparison: Trials comparing a PT intervention with control (including sham) or no intervention and trials comparing two or more PT interventions will be included.

Types of outcome measures:

- Primary outcomes: Fatigue is assessed as the primary outcome at the end of the intervention period, and during follow-up as measured by:

1- Questionnaires that primarily assessed fatigue, such as: Fatigue Severity Scale (FSS; [26]), 
Modified Fatigue Impact Scale (MFIS; [27]), Multidimensional Fatigue Index (MFI; [28]), Visual Analogue Scale for fatigue.

2- Sub-scales of questionnaires that measured fatigue or sub-scales not primarily designed for the assessment of fatigue but used in such, for example: Short Form-36 sub-scale (SF-36; e.g. vitality sub-scale; [29]), and MS Quality of Life 54 (MSQoL-54; e.g. physical functioning subscale; [30]). These sub-scales are only used if it is specifically noted that these were included to assess fatigue.

- Secondary outcomes included: Safety of the intervention, assessed as number of patients with Adverse Events (AEs).

\section{Language:}

Studies written and published in English will be only included.

\section{Search strategy:}

Search methods for identification of studies:

1- Searching electronic data bases: The following sources will be searched from inception to January 2018:

- The Cochrane Central register of controlled trials.

- PubMed.

- Physiotherapy Evidence Database (PEDro).

- Google scholar.

2- Hand searching.

3- Searching other resources: To identify other relevant trial data:

- Authors of published trials will be contacted when reported data were incomplete;

- Reference lists of review articles and primary trials found will be Screened; and

- Experts in the field will be contacted to identify further published or unpublished trials.

Key words:

The following key words are used in the initial search strategy. Medical subheading $(\mathrm{MeSH})$ terms are also utilized when the database offered this option. The search strategy will be adjusted for each database.

"Exercise" or "physical therapy modalities" or "exercise movement techniques" or "movement" or "physical fitness" or "physical rehabilitation" or "physical endurance" or "physical stimulation" or "physical training" or "physical medicine" or "physical therapy" or "recovery of function" or "endurance training" or "resistance training" or "strength training" or "hydrotherapy" or "aquatic therapy" or "underwater exercise" or "vestibular rehabilitation" or "electromagnetic field" or "neurophysiotherapy" or "neurological physical therapy" or "physiotherapy" or "physical therapy techniques" OR physical therapy [MeSH].

And: "Physical fatigue" or "mental fatigue" or "central fatigue" or "quality of life" or "fatigue" or "chronic fatigue" or "fatigability" or "fatigue impact" or "muscle fatigue" or "chronic fatigue syndrome" or "sleep" or "sleep disorder" or "tiredness" or "exhaustion" or "lassitude" or fatigue [MeSH].

And: "Multiple sclerosis" or "optic neurit*" or "encephalomyelitis" or "myelooptic neuropathy" or "myelitis" or "neuromyelitis" or "demyelinating" or "disseminated sclerosis" or multiple sclerosis [MeSH].

\section{Selection of studies:}

Two review authors will independently scan the abstract, title, or both, of every record retrieved, to determine which studies should be assessed further. All potentially-relevant articles as full text will be investigated.

\section{Exclusion criteria:}

- Non RCTs.

- If they targeted non adults (age younger than 18 years old).

- Populations other than MS.

\section{Data extraction and management:}

For studies that fulfill inclusion criteria, two review authors were independently abstract key participant and intervention characteristics and report data on efficacy outcomes and adverse events using standard data extraction templates, with any disagreements to be resolved by discussion, or if required by a third author.

Assessment of risk of bias in included studies:

Two review authors will assess the risk of bias of each included study independently. Disagreements will be resolved by consensus, or by consultation with a third author.

Risk of bias will be assessed using the Cochrane Collaboration's tool for assessment of risk of bias [31].

The following criteria will be assessed in this assessment:

- Random sequence generation (selection bias). 
-Allocation concealment (selection bias).

- Blinding (performance bias and detection bias), blinding of participants and personnel assessed separately from blinding of outcome assessment.

- Incomplete outcome data (attrition bias).

- Selective reporting (reporting bias).

- Other bias.

'Risk of bias criteria' will be judged as 'low risk', 'high risk' or 'unclear risk' and individual bias items will be evaluated as described in the Cochrane
Handbook for Systematic Reviews of Interventions [31].

A 'Risk of bias' graph and a 'Risk of bias summary' figure will be presented.

\section{Quality assessment of the methodology:}

All the included studies were scored on their methodological rigour with the Physiotherapy Evidence Database (PEDro) scale. The PEDro scale examines 11 aspects of the quality of methodology.

Table (1): Search results.

\begin{tabular}{llccc}
\hline & Search strategy & PubMed results Cochrane results PEDro results Google results \\
\hline \#1 & Fatigue & 105188 & 294 & 294 \\
\#2 & Multiple sclerosis & 88166 & 801 & $4,110,000$ \\
\#3 & Physical Therapy interventions & 26423 & 6382 & 601 \\
\#4 & Fatigue and Physical Therapy interventions & 1401 & 117 & $1,810,000$ \\
\#5 & Multiple sclerosis and Physical Therapy interventions & 429 & 38 & $3,140.000$ \\
\#6 & Fatigue and multiple sclerosis & 3166 & 11 & 638,000 \\
\hline
\end{tabular}

Table (2): PEDRO scale.

\begin{tabular}{|c|c|c|c|c|c|c|c|c|c|}
\hline Criteria & $\begin{array}{c}\text { Nedeljko } \\
\text { et al. } \\
(2015)\end{array}$ & $\begin{array}{l}\text { i Mostert a } \\
\text { Kesselring } \\
(2002)\end{array}$ & $\begin{array}{l}\text { nd Hein } \\
\text { et al. } \\
(2017)\end{array}$ & $\begin{array}{l}\text { e Ahm } \\
\text { et al. } \\
(2013)\end{array}$ & $\begin{array}{l}\text { adi Ayd } \\
\text { et al. } \\
(2014)\end{array}$ & $\begin{array}{c}\text { in Ama } \\
\text { et al. } \\
(2019)\end{array}$ & $\begin{array}{c}\text { atya Sto } \\
\text { et al. } \\
(2006)\end{array}$ & $\begin{array}{c}\text { Arab I } \\
\text { et al. } \\
(2019)\end{array}$ & $\begin{array}{c}\text { Navipoura } \\
\text { et al. } \\
(2006)\end{array}$ \\
\hline 1- Specified eligibility criteria & Yes & No & Yes & Yes & Yes & Yes & Yes & Yes & Yes \\
\hline 2- Random allocation of participants & No & Yes & No & No & Yes & No & Yes & No & No \\
\hline 3- Concealed allocation & No & Yes & No & Yes & No & No & No & No & No \\
\hline 4- Similar prognosis at baseline & Yes & Yes & Yes & Yes & Yes & Yes & Yes & Yes & Yes \\
\hline 5- Blinded participant & No & Yes & Yes & Yes & No & No & No & No & No \\
\hline 6- Blinded therapists & No & Yes & Yes & Yes & Yes & No & No & No & No \\
\hline 7- Blinded assessors & Yes & Yes & Yes & Yes & Yes & Yes & Yes & Yes & Yes \\
\hline $\begin{array}{l}\text { 8- More than } 85 \% \text { follow-up for at least one key } \\
\text { outcome }\end{array}$ & Yes & Yes & No & Yes & Yes & Yes & Yes & Yes & Yes \\
\hline 9- 'Intention to treat' analysis & Yes & No & Yes & Yes & No & Yes & Yes & Yes & Yes \\
\hline $\begin{array}{l}\text { 10- Between group statistical analysis for at least } \\
\text { one key outcome }\end{array}$ & Yes & Yes & Yes & Yes & Yes & Yes & Yes & Yes & Yes \\
\hline $\begin{array}{l}\text { 11- Point estimates of variability for at least one key } \\
\text { out come }\end{array}$ & Yes & Yes & No & Yes & Yes & Yes & Yes & Yes & Yes \\
\hline PEDro score & $6 / 10$ & $8 / 10$ & $7 / 10$ & $8 / 10$ & $7 / 10$ & $6 / 10$ & $7 / 10$ & $6 / 10$ & $6 / 10$ \\
\hline
\end{tabular}

(PEDro, 2010).

The PEDro scale considers two aspects of trial quality, namely the "believability" (or "internal validity") of the trial and whether the trial contains sufficient statistical information to make it interpretable. It does not rate the "meaningfulness" (or "generalisability" or "external validity") of the trial or the size of the treatment effect. The first item on the PEDro scale (the item on eligibility criteria) is related to external validity, so it does not reflect the dimensions of quality assessed by the PEDro scale. This item is not used to calculate the method score (which is why the 11 item scale gives a score out of 10).

According to the PEDro guidelines, a positive answer to each of the criteria 2 to 11 will yield one point, obtaining a PEDro score between 0 to 10 [32].
Papers that had a PEDro score of seven or higher, would be considered of 'high quality' while those with a PEDro score of five or six would be considered of 'moderate quality' and those with a PEDro score of four or less would be considered of 'poor quality'.

\section{Assessment of risk of bias of included studies:}

The review authors independently assess risk of bias of included studies, based on the Cochrane Handbook for Systematic Reviews of Interventions [31]. A bias is a systematic error, or deviation from the truth, in results or inferences. Biases can operate in either direction: Different biases can lead to underestimation or overestimation of the true intervention effect. Biases can vary in magnitude. Even a particular source of bias may vary in direc- 
tion: Bias due to a particular design flaw (e.g. lack of allocation concealment) may lead to underestimation of an effect in one study but overestimation in another study. It is usually impossible to know to what extent biases have affected the results of a particular study. The six items represented the risk of bias are shown in (Table 5).

\section{Data synthesis and statistical analysis:}

Review Manager Program for windows (RevMan software, version 5) was used to perform meta-analysis. Fatigue is assessed as the primary outcome at the end of the intervention period, and during follow-up as measured by questionnaires that primarily assessed fatigue by FSS, MFIS, VAS, and MSQoL-54 to study the effectiveness of physical therapy interventions for fatigue in multiple sclerosis patients. To allow comparison of data from different scales, pooled statistics was calculated using Standardized Mean Differences (SMDs), which were computed using RevMan software. Means and Standard Deviations (SDs) for exercise therapy group and control group were used to compute SMDs. The forest plots were computed by means, SD, and sample size effect for exercise group versus control group for each study enters in meta-analysis. If appropriate, estimated effect size was calculated if the outcome variable was reported in $\geq 2$ studies. All outcomes (FSS, MFIS, VAS, and MSQoL-54) were continuous variables. Outcomes were pooled across studies and analyzed using a fixed-effects model for data collated from all eligible acute studies obtained from review and data collated from all eligible intervention studies obtained from review. Outcomes measures used different scales of measurements with $95 \%$ CIs were used to investigate differences. Heterogeneity measures the variability between studies using the ${ }^{12}$ statistic to quantify the proportion of the total outcome attributed to variability among studies. Study variability and heterogeneity was tested by fixed effects model and $\mathrm{I}^{2}$ statistic (Higgins and Gereed, 2011). The following values were used: $\mathrm{I}^{2}=0 \%-30 \%$ (no heterogeneity); $\mathrm{I}^{2}=30 \%-49 \%$ (moderate heterogeneity); $I^{2}=50 \%-74 \%$ (substantial heterogeneity); and $\mathrm{I}^{2}=75 \%-100 \%$ (considerable heterogeneity).

\section{Results}

Study selectionare presented in (Table 3).

- Study characteristics: 4).

Study characteristics are presented in (Table

\section{- Risk of bias within studies:}

Data on risk of bias for each included study are shown in (Table 5).

\section{- Fatigue results:}

There was very high heterogeneity in fatigue severity scale among studies ( $\mathrm{n}=7$ studies, $\mathrm{n}=941$ participants, $\left.p<0.00001 ; \mathrm{I}^{2}=95 \%\right)$. There was significant overall effect between exercise therapy group and control group in fatigue by fatigue severity scale $(\mathrm{SMD}=-1.24 ; 95 \% \mathrm{CI},-1.38$ to $-1.10 ; p<0.00001$, Forest plot 1-A).

There was very high heterogeneity in modified fatigue impact scale among studies $(\mathrm{n}=2$ studies, $\mathrm{n}=131$ participants, $p=0.004 ; \mathrm{I}^{2}=88 \%$, Forest plot 1-B). There was significant overall effect between exercise therapy group and control group in fatigue by modified fatigue impact scale $(\mathrm{SMD}=-0.57$; $95 \% \mathrm{CI},-0.93$ to $-0.22 ; p=0.002$ ).

There was very high heterogeneity in visual analogue scale among studies ( $\mathrm{n}=3$ studies, $\mathrm{n}=234$ participants, $p<0.00001 ; \mathrm{I}^{2}=98 \%$, Forest plot 1 C). There was significant overall effect between exercise therapy group and control group in fatigue by visual analogue scale $(\mathrm{SMD}=0.96 ; 95 \% \mathrm{CI}$, 0.66 to $1.27 ; p<0.00001)$.

Table (3): Study selectionare presented.

\begin{tabular}{|c|c|}
\hline Study & Title \\
\hline Amatya et al. (2019) & - Rehabilitation for people with multiple sclerosis: an overview of Cochrane Reviews. \\
\hline Arab et al. (2019) & - The effect of massage therapy on fatigue of patients with multiple sclerosis. \\
\hline Aydin et al. (2014) & $\begin{array}{l}\text { - Evaluation of the effectiveness of home based or hospital based calisthenic exercises in patients with multiple } \\
\text { sclerosis. }\end{array}$ \\
\hline Ahmadi et al. (2013) & $\begin{array}{l}\text { - Comparison of the Effect of } 8 \text { weeks Aerobic and Yoga Training on Ambulatory Function, Fatigue and Mood } \\
\text { Status in MS Patients. }\end{array}$ \\
\hline Mostert and Kesselring (2002) & $\begin{array}{l}\text { - Activity level of subjects with multiple sclerosis effects of a short-term exercise training program on aerobic } \\
\text { fitness, fatigue, health perception and. }\end{array}$ \\
\hline Nedeljkovi et al. (2015) & - Effectiveness of rehabilitation in multiple sclerosis relapse on fatigue, self-efficacy and physical activity. \\
\hline Navipoura et al. (2006) & - Improved fatigue in individuals with multiple sclerosis after participating in a short-term self-care programme. \\
\hline Heine et al. (2017) & $\begin{array}{l}\text { - Does aerobic training alleviate fatigue and improve societal participation in patients with multiple sclerosis? } \\
\text { A randomized controlled trial. }\end{array}$ \\
\hline Stor et al. (2006) & - The efficacy of multidisciplinary rehabilitation in stable multiple sclerosis patients. \\
\hline
\end{tabular}


Table (4): Study characteristics are presented.

\begin{tabular}{|c|c|c|c|c|c|c|c|c|c|}
\hline & Amatya et al. (2019) & Arab et al. (2019) & $\begin{array}{l}\text { Aydin et al. } \\
\quad(2014)\end{array}$ & $\begin{array}{l}\text { Ahmadi et al. } \\
\text { (2013) }\end{array}$ & $\begin{array}{c}\text { Mostert and } \\
\text { Kesselring (2002) }\end{array}$ & $\begin{array}{l}\text { Nedeljkovi et al. } \\
\text { (2015) }\end{array}$ & $\begin{array}{l}\text { Navipoura et al. } \\
\text { (2006) }\end{array}$ & $\begin{array}{l}\text { Heine et al. } \\
\text { (2017) }\end{array}$ & $\begin{array}{l}\text { Stor et al. } \\
\text { (2006) }\end{array}$ \\
\hline Intervention & $\begin{array}{l}\bullet \text { Unidisciplinary therapy, e.g. } \\
\text { physiotherapy or } \\
\text { occupational therapy only, } \\
\text { and other interventions. } \\
\text { - Multidisciplinary } \\
\text { rehabilitation programmes, } \\
\text { defined as any co-ordinated } \\
\text { therapy programme delivered } \\
\text { by two or more disciplines } \\
\text { (occupational therapy, } \\
\text { physiotherapy, exercise } \\
\text { physiology, prosthetics and } \\
\text { orthotics, speech and } \\
\text { language therapy, diet, and } \\
\text { nursing care), in conjunction } \\
\text { with medical input } \\
\text { (neurologist or rehabilitation } \\
\text { medicine physician) that } \\
\text { aimed to achieve patient- } \\
\text { centred goals. }\end{array}$ & & $\begin{array}{l}- \text { Calisthenic } \\
\text { exercises } \mathbf{t} \\
\text { for } 12 \\
\text { weeks. }\end{array}$ & 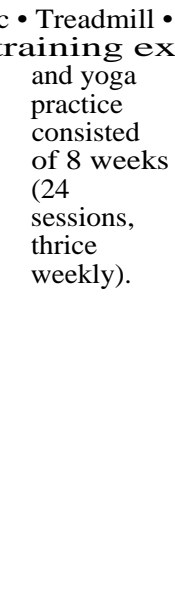 & $\begin{array}{l}\text { - Aerobic } \\
\text { xercise } \\
\text { training for } 4 \\
\text { weeks. Training } \\
\text { intervention } \\
\text { consisted of } \\
\text { 5£30min } \\
\text { sessions per } \\
\text { week of bicycle } \\
\text { exercise with } \\
\text { individualised } \\
\text { intensity. }\end{array}$ & $\begin{array}{l}\text { - Multidisciplinary } \\
\text { Rehabilitation (MDR) } \\
\text { programme which } \\
\text { consisted of two parts. The } \\
\text { first part took place at } \\
\text { Neurology Clinic, during } \\
\text { the IVMP treatment and } \\
\text { included provision of } \\
\text { mobility aids, bladder } \\
\text { management and } \\
\text { instruction on some basic } \\
\text { exercises based on actual } \\
\text { neurological status of } \\
\text { patients, which were } \\
\text { afterwards performed at } \\
\text { home for } 5 \text { days. The } \\
\text { second part included an } \\
\text { outpatient rehabilitation } \\
\text { programme that started 1- } \\
3 \text { days after the IVMP } \\
\text { treatment. }\end{array}$ & $\begin{array}{l}\text { - Self-managed graded } \\
\text { exercises techniques } \\
\text { for } 6 \text { weeks. }\end{array}$ & $\begin{array}{l}\cdot 16 \text {-week aerobic } \cdot \\
\text { s training or } \\
\text { control } \\
\text { intervention. }\end{array}$ & $\begin{array}{l}- \text { The } \\
\text { interventio } \\
\text { n group } \\
\text { were } \\
\text { offered } \\
\text { comprehe } \\
\text { nsive, } \\
\text { multidisci } \\
\text { plinary } \\
\text { inpatient } \\
\text { rehabilitati } \\
\text { on at the } \\
\text { Haslev MS } \\
\text { Hospital } \\
\text { for an } \\
\text { average of } \\
35.5 \text { days. }\end{array}$ \\
\hline $\begin{array}{l}\text { - Control } \\
\text { intervention }\end{array}$ & - Didn't practice. & - Routine medical care. & $\begin{array}{l}\text { - Didn't } \\
\text { practice. }\end{array}$ & $\begin{array}{l}\text { - The control } \\
\text { group } \\
\text { followed } \\
\text { their own } \\
\text { routine } \\
\text { treatment } \\
\text { program }\end{array}$ & - Didn't practice. & $\begin{array}{l}\text { - Control group was treated } \\
\text { in accordance with a } \\
\text { standard procedure, which } \\
\text { does not recommend } \\
\text { regular inclusion into } \\
\text { rehabilitation programme } \\
\text { after IVMP treatment. }\end{array}$ & - Didn't practice. & $\begin{array}{l}\text { - Low-intensity } \\
\text { control } \\
\text { intervention. }\end{array}$ & $\begin{array}{l}- \text { The control } \\
\text { group } \\
\text { received no } \\
\text { treatment } \\
\text { related to } \\
\text { the study. }\end{array}$ \\
\hline $\begin{array}{l}\text { - Outcome of } \\
\text { interest }\end{array}$ & Fatigue. & - Fatigue. & - Fatigue. & - Fatigue. & - Fatigue. & • Fatigue. & - Fatigue. & - Perceived fatigue. & - Fatigue. \\
\hline - Measures & - Fatigue severity scale (FSS). & $\begin{array}{l}\text { - Fatigue severity scale, fatigue } \\
\text { reducing methods, and visual } \\
\text { scale of the effectiveness of } \\
\text { massage therapy. }\end{array}$ & $\begin{array}{l}\text { Fatigue } \\
\text { Severity } \\
\text { Scale. }\end{array}$ & $\begin{array}{l}- \text { Fatigue, } \\
\text { was } \\
\text { measured } \\
\text { by Fatigue } \\
\text { Severity } \\
\text { Scale } \\
\text { (FFS). }\end{array}$ & $\begin{array}{l}\text { - Fatigue Severity } \\
\text { Scale (FSS). }\end{array}$ & $\begin{array}{l}\text { - Fatigue Severity Scale } \\
\text { (FSS). }\end{array}$ & $\begin{array}{l}\text { - Visual analogue } \\
\text { scale. }\end{array}$ & $\begin{array}{l}\text { - Perceived fatigue } \\
\text { (checklist } \\
\text { Individual } \\
\text { Strength } \\
\text { (CIS20r) fatigue } \\
\text { subscale). }\end{array}$ & $\begin{array}{l}\text { - Visual } \\
\text { analogue } \\
\text { scale. }\end{array}$ \\
\hline - Results & $\begin{array}{l}\text { - Significant improvement of } \\
\text { FSS. }\end{array}$ & $\begin{array}{l}- \text { The mean score of fatigue } \\
\text { severity was } 47.72 \pm 10.25 \\
\text { before intervention in the } \\
\text { control group and it was } \\
48.30 \pm 9.78 \text { before } \\
\text { intervention in the } \\
\text { intervention group ( } p=0.7) \text {. } \\
\text { After the intervention, the } \\
\text { mean of fatigue severity was } \\
46.91 \pm 7.07 \text { in the control } \\
\text { group and it was } 43.89 \pm 8.33 \\
\text { in the intervention group. } \\
\text { This change was significant } \\
\text { in the intervention group } \\
(p<0.05) \text {. }\end{array}$ & $\begin{array}{l}- \text { No } \\
\text { significant } \\
\text { difference } \\
\text { was } \\
\text { observed in } \\
\text { the FSS } \\
\text { score } \\
(p<0.05) \\
\end{array}$ & $\begin{array}{l}\text { - Significant } \\
\text { improvem le } \\
\text { ent of FSS. c }\end{array}$ & $\begin{array}{l}\text { A tendency to } \\
\text { less fatigue. No } \\
\text { changes were } \\
\text { observed for the } \\
\text { MS-NI group } \\
\text { and the control } \\
\text { groups. }\end{array}$ & $\begin{array}{l}\text { - No significant change in } \\
\text { FSS in both time points, } \\
\text { despite different trend seen } \\
\text { between groups. }\end{array}$ & $\begin{array}{l}\text { score of the patients } \\
\text { was significantly } \\
\text { different before } \\
\text { (53.9) and after } \\
\text { (68.1) the self- } \\
\text { managed graded } \\
\text { exercise programme } \\
(p<0.000) \text {. The score } \\
\text { of fatigue was also } \\
\text { significantly } \\
\text { different before } \\
(4.59) \text { and after } \\
(5.76) \text { the } \\
\text { intervention } \\
(p<0.0001)\end{array}$ & $\begin{array}{l}- \text { An improvement } \\
\text { of } \geq 8 \text { points on } \\
\text { the CIS20r } \\
\text { fatigue subscale } \\
\text { was considered } \\
\text { clinically } \\
\text { relevant. } \\
\text { Outcomes were } \\
\text { assessed by a } \\
\text { blinded observer } \\
\text { at baseline, } 2,4, \\
6 \text { and } 12 \text { months. }\end{array}$ & $\begin{array}{l}- \text { No } \\
\text { statistically } \\
\text { significant } \\
\text { differences } \\
\text { between } \\
\text { the two } \\
\text { groups in } \\
\text { any of the } \\
\text { outcome } \\
\text { measures. }\end{array}$ \\
\hline
\end{tabular}

Unidisciplinary therapy, e.g. $\bullet$ A massage therapy program.

Multidisciplinary

Self-managed graded $\bullet$ 16-week aerobic $\bullet$ The occupational therapy only, and other interventions.

rehabilitation programmes, therapy programme delivere

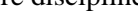
hysiotherapy, exercise physiology, prosthetics an anguage therapy, diet, an ursing care), in conjunction neurologist or rehabilitation imed to achieve patientcentred goals.

The control $\bullet$ Didn't practice. .

measured

by Fatigue
Severity

he self-esteen

The mean score of fatigue - A tendency to $\bullet$ No significant change in ore of the patients of $\geq 8$ points on stast before intervention in the difference ent of FSS. changes were despite different trend seen . was he FSS the between groups.

(53.9) and after
(68.1) the selfmanaged graded exercise programme in the intervasion in the interve
$(p<0.05)$. 
Table (5): Data on risk of bias for each included study.

\begin{tabular}{|c|c|c|c|c|c|c|c|c|c|}
\hline Criteria & $\begin{array}{l}\text { Nedeljkovi } \\
\text { et al. (2015) }\end{array}$ & $\begin{array}{c}\text { Mostert and } \\
\text { Kesselring } \\
\text { (2002) }\end{array}$ & $\begin{array}{l}\text { Heine } \\
\text { et al. } \\
(2017)\end{array}$ & $\begin{array}{l}\text { Ahmadi et al. } \\
\text { (2013) }\end{array}$ & $\begin{array}{l}\text { Aydin } \\
\text { et al. } \\
(2014)\end{array}$ & $\begin{array}{l}\text { Amatya } \\
\text { et al. } \\
(2019)\end{array}$ & $\begin{array}{c}\text { Stor } \\
\text { et al. } \\
(2006)\end{array}$ & $\begin{array}{c}\text { Arab } \\
\text { et al. } \\
(2019)\end{array}$ & $\begin{array}{c}\text { Navipoura } \\
\text { et al. } \\
(2006)\end{array}$ \\
\hline 1- Sequence generation. & - Unclear & - Unclear & - Unclear & - Unclear & Clear & Unclear & Clear & Clear & Unclear \\
\hline 2- Allocation concealment. & - Clear & - Unclear & - Clear & - Unclear & Unclear & Clear & Unclear & Unclear & Clear \\
\hline 3- Blinding of participants, personnel & - No (outcome & - Yes & - Yes & - No (outcome & Yes & Yes & Yes & No & No \\
\hline and outcome assessors & assessors only) & & & assessors only) & & & & & \\
\hline 4- Incomplete outcome data addressed & - Unclear & - Year & $\cdot$ No & $\bullet$ No & Yes & Yes & No & No & Yes \\
\hline 5- Selective outcome reporting. & - Yes & - Yes & - Yes & - No & No & No & No & Yes & Yes \\
\hline 6- Free of other sources of bias. & - Yes & - Yes & - Yes & - Yes & Yes & No & Yes & Yes & No \\
\hline
\end{tabular}

A- FSS meta-analysis

\begin{tabular}{|c|c|c|c|c|c|c|c|c|c|c|c|c|c|}
\hline \multirow{2}{*}{$\begin{array}{l}\text { Study or Subyroup } \\
\text { Mostert and Kesselring (2002) }\end{array}$} & \multicolumn{3}{|c|}{ Exercise therapy } & \multicolumn{3}{|c|}{ Control } & \multicolumn{2}{|r|}{ Std. Mean Difference } & \multirow[b]{2}{*}{ Year } & \multirow{2}{*}{\multicolumn{3}{|c|}{$\begin{array}{l}\text { Std. Mean Difference } \\
\text { IV, Fixed, } 95 \% \mathrm{Cl}\end{array}$}} & \\
\hline & Mean & \multicolumn{2}{|c|}{ SD Total } & Mean & \multicolumn{2}{|c|}{ SD Total } & \multirow[b]{2}{*}{\begin{tabular}{r|} 
Weight \\
$3.3 \%$ \\
$2.6 \%$ \\
$4.3 \%$ \\
$5.2 \%$ \\
$8.5 \%$ \\
$10.6 \%$ \\
$65.5 \%$
\end{tabular}} & \multirow[b]{2}{*}{\begin{tabular}{c}
\multicolumn{1}{c}{ IV, Fixed, 95\% Cl } \\
$-0.31[-1.10,0.48]$ \\
$-0.44[-1.33,0.45]$ \\
$0.06[-0.63,0.75]$ \\
$-0.21[-0.84,0.42]$ \\
$0.09[-0.40,0.58]$ \\
$-0.41[-0.85,0.04]$ \\
$-1.79[-1.97,-1.61]$
\end{tabular}} & & & & & \\
\hline $\begin{array}{l}\text { Mostert and Kesselring (2002) } \\
\text { Ahmadi et al. (2013) } \\
\text { Aydin et al. (2014) } \\
\text { Nedeljkovi et al. (2015) } \\
\text { Heine et al. (2017) } \\
\text { Arab et al. (2019) } \\
\text { Amatya et al. (2019) }\end{array}$ & $\begin{array}{r}4.4 \\
3.46 \\
4.86 \\
36.6 \\
5.2 \\
43.89 \\
31.6\end{array}$ & $\begin{array}{r}1.9 \\
1.77 \\
1.16 \\
21.1 \\
1.1 \\
8.33 \\
4.6\end{array}$ & $\begin{array}{r}12 \\
10 \\
16 \\
19 \\
33 \\
404 \\
341\end{array}$ & $\begin{array}{r}5 \\
4.17 \\
4.79 \\
40.6 \\
5.1 \\
47.72 \\
39.5\end{array}$ & $\begin{array}{r}1.9 \\
1.28 \\
1.18 \\
15.9 \\
1.1 \\
10.25 \\
4.2\end{array}$ & $\begin{array}{r}13 \\
10 \\
16 \\
20 \\
30 \\
40 \\
341\end{array}$ & & & $\begin{array}{l}2002 \\
2013 \\
2014 \\
2015 \\
2017 \\
2019 \\
2019\end{array}$ & \multirow[t]{2}{*}{$\cdot$} & $\overline{-}-\overline{ }$ & + & \\
\hline Total $(95 \% \mathrm{Cl})$ & & & 471 & & & 470 & $100.0 \%$ & & & & & & \\
\hline \multicolumn{9}{|c|}{$\begin{array}{l}\text { Heterogeneity: } \mathrm{Chi}^{2}=110.56, \mathrm{df}=6(p<0.00001) ; I^{2}=95 \% \\
\text { Test for overall effect: } Z=16.87(p<0.00001)\end{array}$} & & -2 & -1 ise therapy & Control 1 & 2 \\
\hline
\end{tabular}

B- MFIS meta-analysis

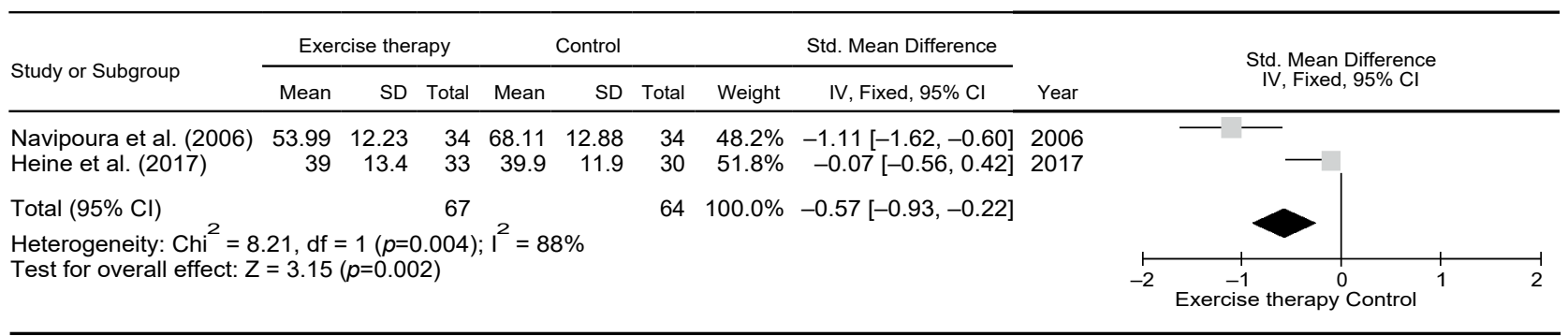

C- VAS meta-analysis

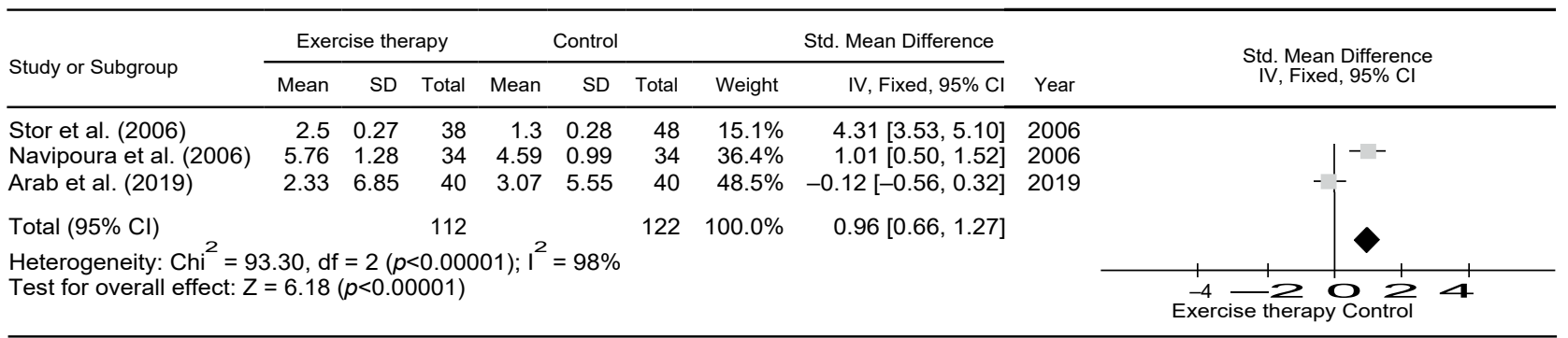

Forest plot (1): Overall analysis of fatigue by FSS, MFIS, and VAS.

There was no heterogeneity in multiple sclerosis quality of life-54 among studies ( $n=4$ studies, $n=177$ participants, $p=0.62 ; I^{2}=0 \%$, Forest plot 2$)$. There was significant overall effect between exercise therapy group and control group in fatigue by multiple sclerosis quality of life-54 (SMD=0.35; $95 \%$ CI, 0.05 to $0.65 ; p=0.02$ ). Sensitivity analysis showed that fatigue assessed by multiple sclerosis quality of life-54 was non-significant by excluding one trial at a time from pooled effects to determine whether any one study was particularly influential. No significant or change in heterogeneity $\left(\mathrm{I}^{2}=0 \%\right)$ among including four studies was observed after removal one study according to sensitivity analysis matrix. 


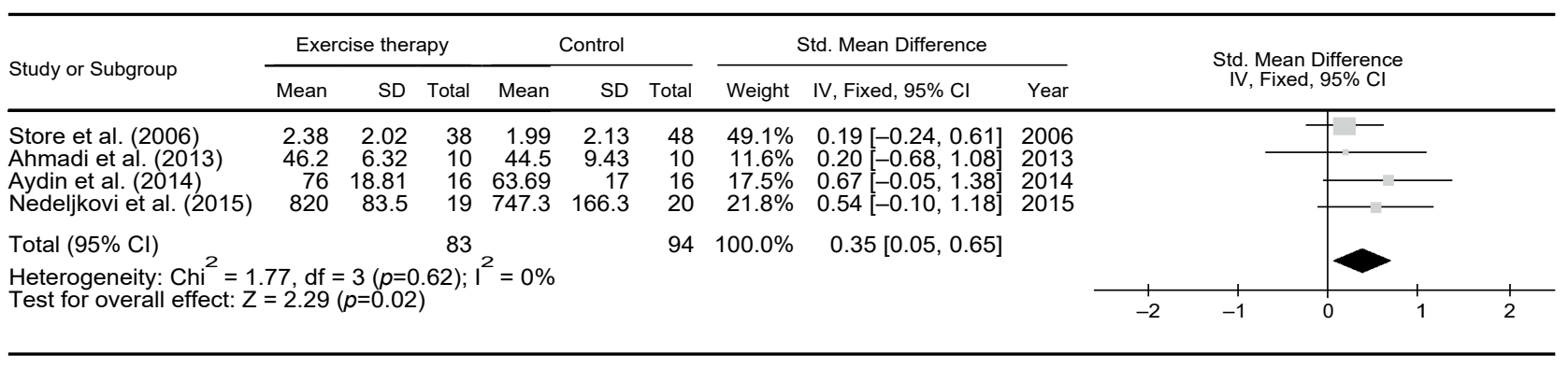

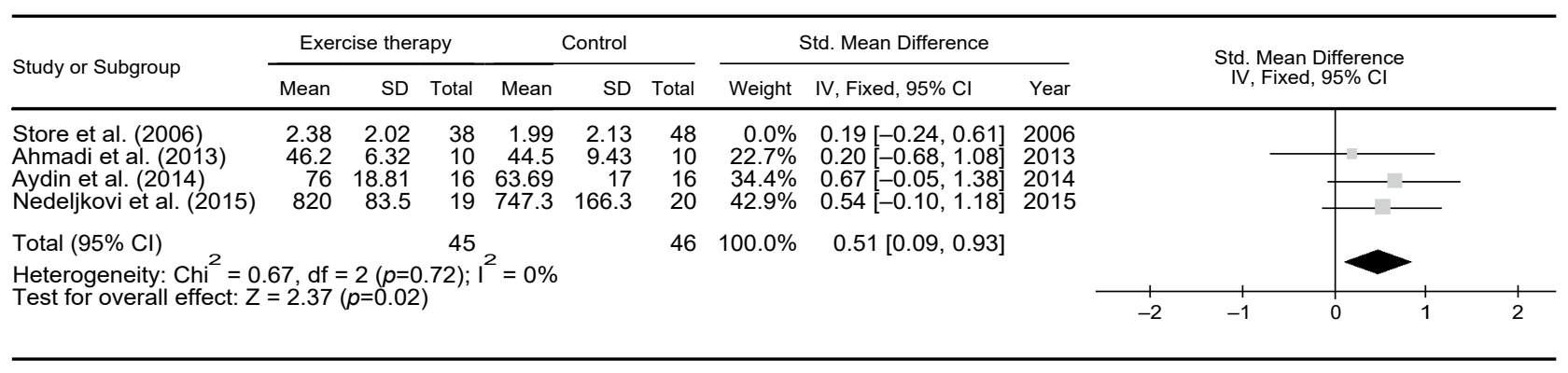

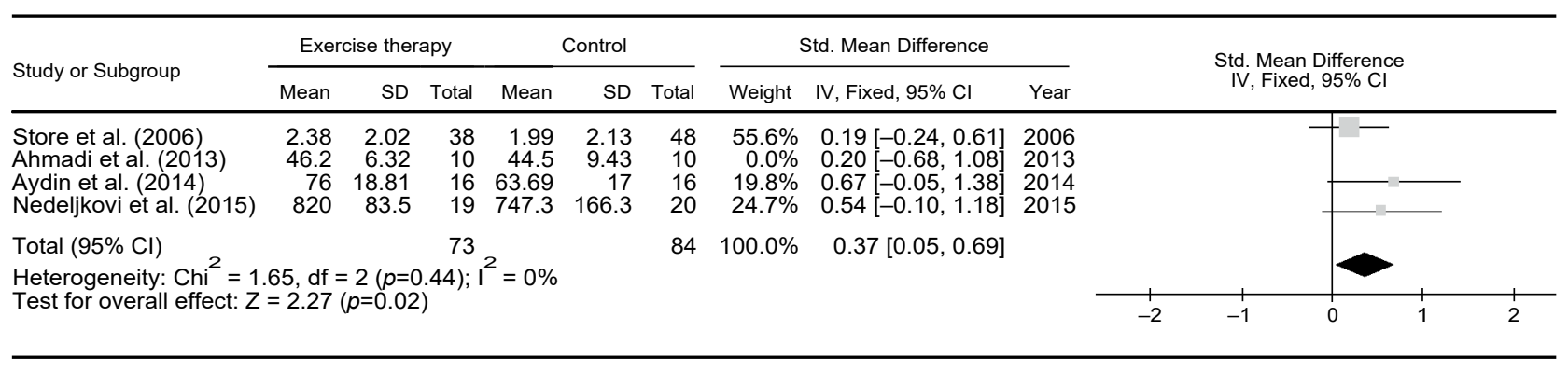

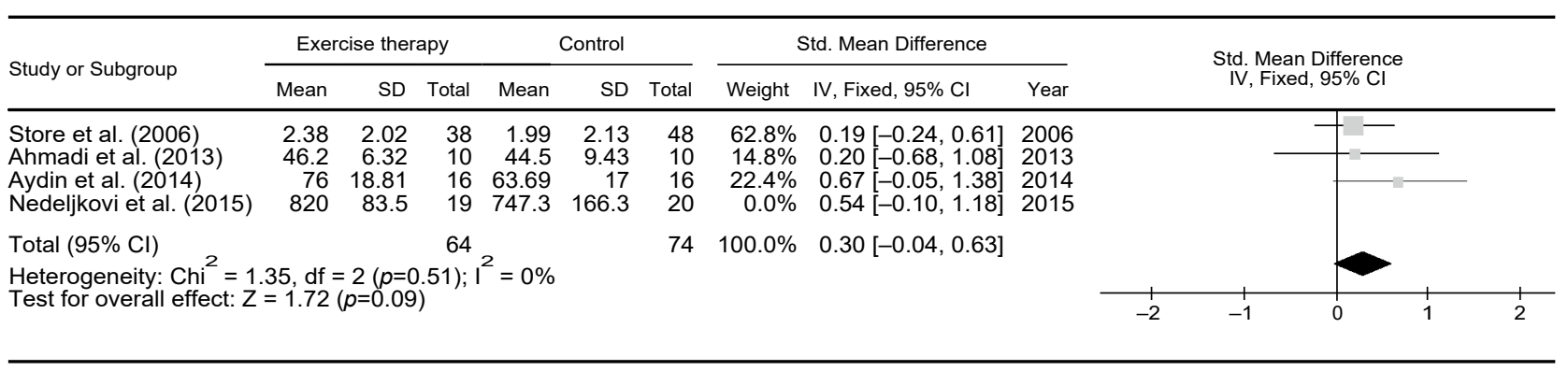

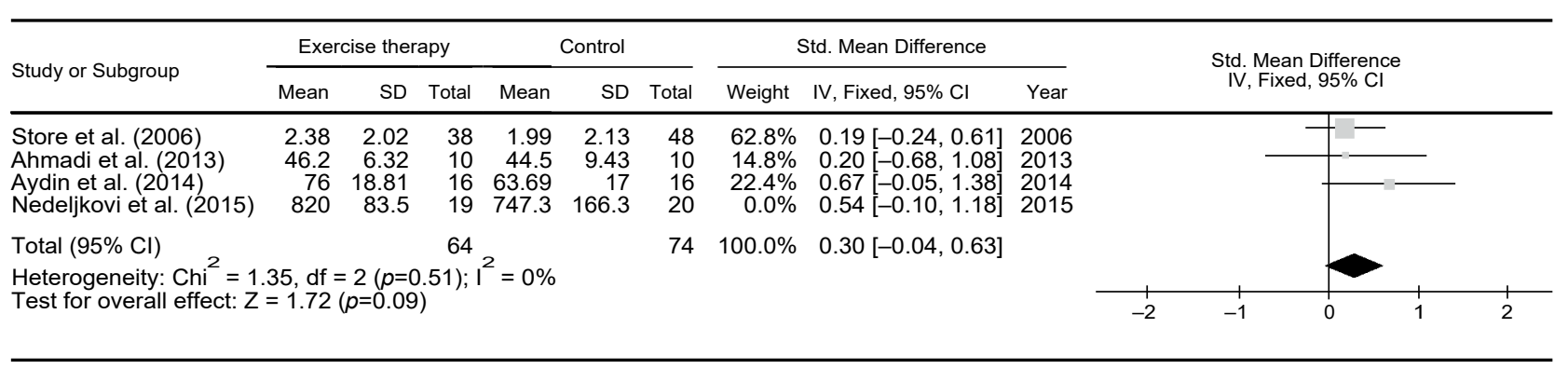




\section{Discussion}

The purpose of the current systematic review is to identify current PT interventions for treatment of fatigue in MS and their evidence-base and to systematically review literature for qualitative evidence for those treatments, which have been investigated, in order to determine their effectiveness and their possible adverse events. This metaanalysis combined data at the study level. Fatigue is assessed as the primary outcome at the end of the intervention period, and during follow-up as measured byquestionnaires that primarily assessed fatigue, such as: Fatigue Severity Scale (FSS), Modified Fatigue Impact Scale (MFIS), Visual Analogue Scale (VAS), and MS Quality of Life 54 (MSQoL-54) to study the effectiveness of physical therapy interventions for fatigue in multiple sclerosis patients, this review includes studies published from 2002 up to 2019 and searched on Medline data base through Pub Med and Pedro that most likely include huge amount of papers published each year, Cochrane library also was searched and Google scholar web site.

Most trials used either the FSS or MFIS as fatigue outcome. However, there is no consensus as to whether these scales measure the same construct. Moreover, there increasing evidence that these questionnaires measure deferent aspects of fatigue $[33,34]$. Following Rasch analysis, the FSS was shown to measure the social consequences of fatigue as opposed to the actual intensity or severity of fatigue [35] whereas the MFIS was found valuable in the assessment of cognitive and physical aspects of fatigue, but not general fatigue [36].

In contrast, moderate to high correlation coeDicients between the FSS and MFIS have been found, indicating that the FSS and MFIS, at least in some extent, measure the same construct or are closely related $[\mathbf{3 4 , 3 7 ]}$.

Differences in the construct validity of fatigue outcome measures may be reflected in deferential results of exercise therapy on fatigue. However, a sub-group analysis revealed no significant differences of exercise therapy on fatigue, in this case, between the FSS, MFIS, POMS fatigue subscale, or FSMC Summary of findings 3). Nonetheless, novel fatigue measures, such as the FSMC, have been developed that may provide additional insights on fatigue or may be more sensitive and specific in people with MS [33].

Moreover, in a study conducted by Negahban et al., in 2013 to compare the effects of massage therapy and exercise therapy in MS patients, it was reported that massage therapy was more effective than exercise therapy in reducing the fatigue and muscle spasm and improving the balance of the patients [38].

On the other hand, no study was found on the ineffectiveness or inappropriate effect of nonmedical fatigue reducing methods in MS patients. Among the demographic variables studied in this research, none of them had an effect on fatigue severity, except for the duration of the disease which affected the mean of fatigue severity. Patients who had the disease for a longer period of time expressed less fatigue. This result might be attributed to the habituation of people to experience fatigue. This result was not in line with that of other studies such as Bahreini et al., 2013 and Ghaffari et al., 2008.

In a study that conducted by Aydin et al., 2014, the calisthenic exercises performed at home or in the hospital setting may improve the balance, quality of life, and the psychological status in the patients with MS, while no significant effect has been observed on fatigue. The intergroup comparison revealed that the exercises in the hospital setting are effective only on the depression and balance. Calisthenic exercises are simple and economical exercises which do not require any devices and can be performed both at home and in the hospital setting. Prospective studies in larger patient groups may shed light on the effects of calisthenic exercises in MS in more detail.

Treatment of fatigue in multiple sclerosis is still a challenge, without clear consensus on the best treatment approach. Existing systematic reviews presented dominantly second level of evidence for different rehabilitation procedures and cognitive behavioral therapy [39]. Recent meta analysis showed small effect size for exercises on reduction of fatigue [40]. However, as there are yet no data on management of fatigue in relapse of disease, we had believed that comprehensive rehabilitation during relapse in the group of patients with pronounced symptom of fatigue could have influenced its reduction. Although analysis of our data showed different patterns of change in fatigue scores between the groups, indicating possible influence of provided rehabilitation program, there was no statistically significant difference between the groups in any of the time points.

Data from existing rehabilitation trials in stable phase of disease showed that low frequency (two times a week), but longer duration programs (8- 
12 weeks) are superior to high-frequency shortduration protocols [41].

The study by Rietberg et al., 2010 has shown that, as rehabilitation program was primarily based on exercises and self-implemented fatigue program, it is also possible that such approach was not sufficient to induce higher magnitude of change. A choice of appropriate outcome scale can also be questioned, because FSS does not assess all aspects of fatigue, taking into account dominantly impact of fatigue on daily functioning.

Una et al., 2015 concluded that, rehabilitation started along with corticosteroid treatment induced sustained improvement in physical activity of people with MS. It also enhanced self-efficacy for function and control, but failed to demonstrate reduction in fatigue. Further research should include more subjects and examine various rehabilitation strategies in terms of content, timing and intensity in an attempt to influence patients' recovery after relapse of disease.

Heine et al., 2017 said that despite the small significant positive post-intervention effect and the absence of associated harm, aerobic training does not lead to clinically relevant improvements in MS-related fatigue and societal participation. This conclusion does not imply that aerobic training should not be used in clinical practice. Exercise therapy, and aerobic training in particular, has proven efficacy in the treatment and prevention of physical deconditioning, mobility problems, secondary health risks and potentially in disease progression.

The study by Navipoura et al., 2006 has shown that, self-managed graded exercise program seem to be a useful method in helping the patients to cope with their problems, though a long term controlled trial is warranted to better understand the effect of self-managed graded exercise program on patients with MS. We recommend self-managed graded exercise program as an alternative in rehabilitation of nondisabled patients with MS.

Only published trials were included in the current systematic review, unavailable relevant articles which may show positive or negative results were not included in the review.

From the previous studies it can be concluded that physical therapy interventions should be considered as a treatment supplement for fatigue in patients with multiple sclerosis although we need future research.
Evidence based practice is needed to improve quality of health care. A body of evidence regarding safety, effectiveness, appropriate indications, costeffectiveness, and other attributes of medical care are demanded [42].

As the treatment strategies are rapidly increasing and changeable so in order to cope with the new information about the traditional treatment strategies and the recent strategies so physical therapists have to use the evidence in practice to improve the quality of patient care and to ensure that the best update of treatment is delivered. However, incorporating research into practice is time consuming, and so we need methods of facilitating easy access to evidence for busy clinicians, systematic reviews aim to inform and facilitate this process through research synthesis of multiple studies, enabling increased and efficient access to evidence.

\section{Conclusion:}

According to this review there is enough support to use physical therapy interventions for fatigue in patients with multiple sclerosis.

It appears to be some evidence favoring physical therapy interventions in reducing fatigue in patients with multiple sclerosis.

\section{References}

1- COMPSTON A. and COLES A.: Multiple sclerosis. Lancet, 372: 1502-17, 2008.

2- PUGLiATTI M., et al.: The epidemiology of multiple sclerosis in Europe. Eur. J. Neurol., 13: 700-22, 2006.

3- HASHEM S., EL-TAMAWY M. and HAMDY S.: E.T. Epidemiology of multiple sclerosis in Egypt. Egypt J. Neurol. Psychiat. Neurosurg., 47: 625-32, 2010.

4- TURNER A.P., KIVLAHAN D.R. and HASELKORN J.K.: Exercise and quality of life among people with multiple sclerosis: Looking beyond physical functioning to mental health and participation in life. Arch. Phys. Med. Rehabil., 90: 420-8, 2009.

5- PATWARDHAN M.B., et al.: Cost of multiple sclerosis by level of disability: A review of literature. Mult. Scler., 11: 232-9, 2005.

6- INDURUWA I., CONSTANTINESCU C.S. and GRAN B.: Fatigue in multiple sclerosis-A brief review. J. Neurol. Sci., 323: 9-15, 2012.

7- KOS D., KERCKHOFS E., NAGELS G., D'HOOGHE M.B. and ILSBROUKX S.: Origin of fatigue in multiple sclerosis: Review of the literature. Neurorehabil. Neural. Repair., 22: 91-100, 2008.

8- KRUPP L.B. and SERAFIN D.J.: C.C. Multiple sclerosis associated fatigue. Expert. Rev. Neurother., 10: 1437-47, 2010. 
9- LEAVITT V.M. and SUMOWSKI J.F.: Warmer outdoor temperature is associated with worse cognitive status in multiple sclerosis. Neurology, 78: 964-8, 2012.

10- WHITE P.D., et al.: Comparison of adaptive pacing therapy, cognitive behavior therapy, graded exercise therapy, and specialist medical care for chronic fatigue syndrome (PACE): A randomised trial. Lancet, 377: 82336, 2011.

11- AHLBERG K., EKMAN T., GASTON-JOHANSSON F. and MOCK V.: Assessment and management of cancerrelated fatigue in adults. Lancet, 362: 640-50, 2003.

12- MSCCP Guidelines. Evidence-based management strategies for fatigue in multiple sclerosis. in Fatigue and multiple sclerosis (Paralyzed Veterans Association of America, 1998).

13- SUTHERLAND G.: A.M. Exercise and multiple sclerosis: Physiological, psychological, and quality of life issues. J. Sport. Med. Phys. Fit., 41: 421-32, 2001.

14- DALGAS U., STENAGER E. and INGEMANN-HANSEN T.: Multiple sclerosis and physical exercise: Recommendations for the application of resistance-, endurance-and combined training. Mult. Scler., 14: 35-53, 2008.

15- DALGAS U., et al.: Fatigue, mood and quality of life improve in MS patients after progressive resistance training. Mult. Scler., 16: 480-90, 2010.

16- HEBERT J.R., CORBOY J.R., MANAGO M.M. and SCHENKMAN M.: Effects of Vestibular Rehabilitation on Multiple Sclerosis-Related Fatigue and Upright Postural Control: A Randomized Controlled Trial. Phys. Ther., 91: 1166-83, 2011.

17- SANDYK R.: Treatment with Weak Electromagnetic Fields Improves Fatigue Associated with Multiple Sclerosis. Int. J. Neurosci., 84: 177-86, 1996.

18- KARGARFARD M., ETEMADIFAR M., BAKER P., MEHRABI M. and HAYATBAKHSH R.: Effect of aquatic exercise training on fatigue and health-related quality of life in patients with multiple sclerosis. Arch. Phys. Med. Rehabil., 93: 1701-8, 2012.

19- ABDELGHAFFAR S.: Essentials of Evidence-Based Medicine. Higher Education Enhancement Project Fund, Cairo, 2007.

20- HAYNES R.B., DEVEAUX P.J. and G.G.H. Physician's and patients" choices in evidence-based practice", British Medical Journal, 324-50, 2002.

21- McDONALD W., et al.: Recommended diagnostic criteria for multiple sclerosis: Guidelines from the International panel on the diagnosis of multiple sclerosis. Ann. Neurol., 50: 121-7, 2001.

22- POLMAN C.H., REINGOLD S.C., EDAN G., FILIPPI M., HARTUNG H.P., KAPPOS L., et al.: Diagnostic criteria for multiple sclerosis: 2005 revisions to the 'McDonald Criteria'. Ann. Neurol., 58: 840-6, 2005.

23- POLMAN C.H., et al.: Diagnostic criteria for multiple sclerosis: 2010 revisions to the McDonald criteria. Ann. Neurol., 69: 292-302, 2011.

24- POSER C.M., et al.: New diagnostic criteria for multiple sclerosis: Guidelines for research protocols. Ann. Neurol., 13: 227-31, 1983.
25- APTA. Guide to physical therapist practice. http:// guidetoptpractice.apta.org/, 2016.

26- LAROCCA N.G., MUIR-NASH J., STEINBERG A.D. and LAUREN B.: The fatigue severity scale. Application to patients with multiple sclerosis and systemic lupus erythematosus. Arch. Neurol., 46: 1121-3, 1989.

27- FISK J.D., et al.: Measuring the functional impact of fatigue: Initial validation of the fatigue impact scale. Clin. Infect. Dis., 18 (supplem, S79-S83), 1994.

28- SMETS E.M.A., GARSSEN B., BONKE B. and De HAES, J.C.J.M.: The Multidimensional Fatigue Inventory (MFI) psychometric qualities of an instrument to assess fatigue. J. Psychosom. Res., 39: 315-25, 1995.

29- WARE J.E. and SHERBOURNE C.D.: The MOS 36-item Short-Form Health Survey (SF-36). I. Conceptual framework and item selection. Med. Care, 90: 473-83, 1992.

30- VICKREY B.G., HAYS R.D., HAROONI R., MYERS L.W. and ELLISON G.W.: A health-related quality of life measure for multiple sclerosis. Qual. Life Res., 4: 187206, 1995

31- HIGGINS J.P.T., et al.: The Cochrane Collaboration's tool for assessing risk of bias in randomised trials. BMJ vol. 343, 2011.

32- MAHER C.G. and SHERRINGTON C.: H.R. Reliability of the PEDro scale for rating quality of randomized controlled trials Phys. Ther., 83: 713-21, 2003.

33- ELBERS R.G., RIETBERG M.B., VAN WEGEN E.E., VERHOEF J. and KRAMER S.F.: T. C. B. Self-report fatigue questionnaires in multiple sclerosis, Parkinson's disease and stroke: A systematic review of measurement properties. Quality of Life Research, 21 (6): 925-44. 2012.

34- RIETBERG M.B. and VAN WEGEN E.E.: K.G. Measuring fatigue in patients with multiple sclerosis: Reproducibility, responsiveness and concurrent validity of three Dutch self-report questionnaires. Disabil Rehabil, 32 (22): 18706, 2010.

35- MILLS R., YOUNG C., NICHOLAS R. and PALLANT J.: T.A. Rasch analysis of the Fatigue Severity Scale in multiple sclerosis. Multiple Sclerosis, 15 (1): 81-7, 2009.

36- MILLS R.J., YOUNG C.A. and PALLANT J.F.: T. A. Rasch analysis of the Modified Fatigue Impact Scale (MFIS) in multiple sclerosis. J. Neurol. Neurosurg. Psychiatry, 81: 1049-51, 2010.

37- LEARMONTH Y.C., DLUGONSKI D., PILUTTI L.A., SANDRO B.M. and KLAREN R.: M. R. W. Psychometric properties of the Fatigue Severity Scale and the Modified Fatigue Impact Scale. Journal of Neurological Sciences, 331 (1-2): 102-7, 2013.

38- NEGAHBAN H., REZAIE S. and GOHARPEY S.: Massage therapy and exercise therapy in patients with multiple sclerosis: A randomized controlled pilot study. Clin. Rehabil, 27: 1126-36, 2013.

39- BEER S. and KHAN F.: K.J. Rehabilitation interventions in multiple sclerosis: An overview. J. Neurol., 259.10.1007/ s00415-012-6577-4, 2012.

40- PILUTTI L.A., GREENLEE T.A., MOTL R.W. and NICKRENT M.S., P. S. J.: Effects of exercise training on fatigue in multiple sclerosis: A meta-analysis. Psychosom. Med., 75 (6): 575-80, 2013. 
41- ANDREASEN A.K., JAKOBSEN J., SOERENSEN L., ANDERSEN H., PETERSEN T. and BJARKAM C.R.: A. J. Regional brain atrophy in primary fatigued patients with multiple sclerosis. Neuroimage, 50: 608-15, 2010.
42- MANCHIKANTI L.: Evidence-Based Medicine Systematic Reviews, And Guidelines In Interventional Pain Management, Part I: Introduction and General Considerations Pain Physician, 11: 161-86, 2008.

\section{فعالية تدخلات العلاج الطبيعى فى علاج الإجهاد

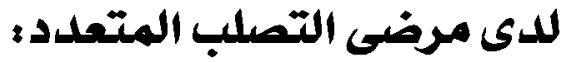

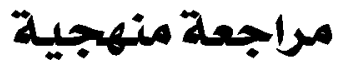

كان الهدف من هذه المراجعة المنهجية هو فصص فاعلية تدخلات العلاج الطبيعى فى علاج الإجهاد لدى مرضى التصلب المتعدد. تم عمل

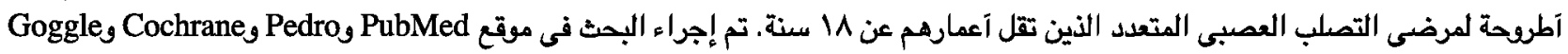

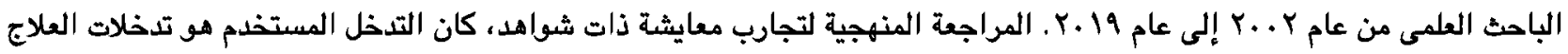

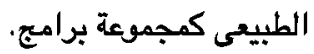

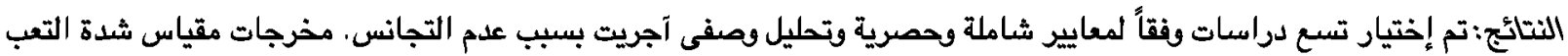

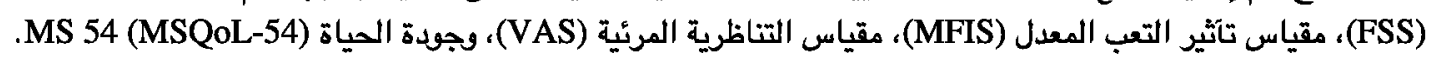

الخلاصدة: يلعم المستوى الحالى من الآدلة فعالية تلخلات العلاج الطبيعى للحد من التعب فى مرضى التصلب المتعدد. 